\title{
First cytogenetic study of Coleorrhyncha: Meiotic complement of Xenophyes cascus (Hemiptera: Peloridiidae)
}

\author{
SNeJANa GROZEVA ${ }^{1}$, Valentina KUZNETSOVA² and VikToR HARTUNG ${ }^{3}$ \\ ${ }^{1}$ Institute of Biodiversity and Ecosystem Research of Bulgarian Academy of Sciences, Tsar Osvoboditel 1, 1000 Sofia, Bulgaria; \\ e-mail: sgrozeva@gmail.com \\ ${ }^{2}$ Zoological Institute of the Russian Academy of Sciences, Universitetskaya nab. 1, 199034 Saint-Petersburg, Russia; \\ e-mail: valentina_kuznetsova@yahoo.com \\ ${ }^{3}$ Museum für Naturkunde, Leibniz-Institute for Research on Evolution and Biodiversity at the Humboldt University Berlin, \\ Invalidenstrasse 43, 10115 Berlin, Germany; e-mail: Viktor.Hartung@mfn-berlin.de
}

Key words. Hemiptera, Coleorrhyncha, Peloridiidae, Xenophyes cascus, meiotic complement, holokinetic chromosomes, male reproductive system

\begin{abstract}
Cytogenetic information on the hemipteran suborder Coleorrhyncha is here provided for the first time. The New Zealand peloridiid species, Xenophyes cascus Bergroth, 1924 (Hemiptera: Coleorrhyncha: Peloridiidae), was found to display testes with a single follicle each, holokinetic chromosomes (like other Hemiptera), a karyotype of $2 n=26+X(0)$ and a single chiasma per bivalent in male meiosis. Comparative analysis of sex chromosome systems in all four hemipteran suborders (Sternorrhyncha, Auchenorrhyncha, Heteroptera and Coleorrhyncha) allowed inference that an $\mathrm{X}(0)$ sex determining system was ancestral within the Hemiptera, whilst the $\mathrm{XY}$-system was most likely a derived condition within the Heteroptera.
\end{abstract}

\section{INTRODUCTION}

Peloridiids (sometimes named "moss bugs") are little-known insects believed to be relict members of an ancient lineage of Hemiptera (Evans, 1982). This taxonomically small group comprises 17 genera and 36 species of small insects (up to $5 \mathrm{~mm}$ long) with a cryptic lifestyle (Burckhardt, 2009; Burckhardt et al., 2011). These "living fossils" inhabit temperate forests and fens of the Southern Hemisphere (Australia, including nearby Lord Howe Island, New Zealand, New Caledonia, Chile, Argentina), where they live in and feed on bryophytes (Evans, 1982; Burckhardt, 2009; Kuechler et al., 2013).

The phylogenetic relationships of peloridiids within the Hemiptera, the largest order in Paraneoptera, have been a matter of contentious debates for a long time. In the past, they have been variously assigned to the Heteroptera or the Homoptera. Today, they are generally considered to be the sole extant family (the Peloridiidae) of the hemipteran suborder Coleorrhyncha, which is treated as the sister group to the suborder Heteroptera (Larivière et al., 2011), though there are data supporting divergent opinions as well (e.g. Cui et al., 2013).

Accumulation of knowledge on various aspects of Peloridiidae biology is important as it can deliver additional insights into the origins of the group as well as the Hemiptera as a whole. Specifically, information on the evolution of cytogenetic systems within the Hemiptera is especially useful. At present, cytogenetic suborder sampling of the Hemiptera is complete with the only exception of the Coleorrhyncha, in which to date no species has been studied with respect to chromosomes. In this paper we close this gap and describe male meiotic karyotype of Xenophyes cascus.

\section{MATERIAL AND METHODS}

Adult males of Xenophyes cascus Bergroth, 1924 were extracted from bryophytes using Berlese-Tullgren funnels (Berlese, 1905; Tullgren, 1918); the bryophytes were collected in Otaki forks, Tararua forest Park, New Zealand. Nine specimens were shipped via airmail alive (in plastic tubes with wet moss) to the laboratory, fixed for $30 \mathrm{~min}$ in $95 \%$ ethanol : glacial acetic acid mixture $(3: 1)$ and dissected in a drop of $45 \%$ acetic acid under a stereoscopic microscope. Gonads were isolated and squashed under a glass coverslip. Slides were first examined under a phasecontrast microscope to check for the availability of meiotic divisions and quality of chromosome spreads. Only a single male was found to display divisions suitable for chromosome analysis. The coverslip was removed by freezing on dry ice; the slide was dehydrated in freshly prepared $3: 1$ fixative for $15 \mathrm{~min}$; air-dried and mounted in a ProLong Gold antifade reagent with DAPI (4',6-diamidino-2-phenylindole) (Invitrogen, Molecular probes, Eugene, Oregon, USA, Cat. No.: P36931). Chromosomes were analyzed under a fluorescent Axio Scope A1 microscope (Carl Zeiss, Jena, Germany) at $100 \times$ magnification and documented with a digital camera, ProgRes MFcool - Jenoptik AG.

All preparations and remains of the specimens are currently stored at the Institute of Biodiversity and Ecosystem Research, BAS, in Sofia.

\section{RESULTS}

In adult male $X$. cascus, reproductive organs occupy the greater part of the abdomen in the first eight segments. The reproductive system consists of a pair of testes extended along the abdomen, each with a single colourless fusiform follicle. The follicle narrows posteriorly to join a short vas deferens which dilates to form the sacciform seminal vesicle. The accessory glands are long and connect to the beginning of the post-vesicular deferent ducts (Fig. 1). On each side of the abdomen, bacteriomes [specialized structures in the body of certain insects which harbour endosymbiontic bacteria (Müller, 1951)] are present as three spherical masses.

In the male of $X$. cascus examined, approximately 30 nuclei at the metaphase first (MI) stage of meiosis were analysed. Of particular note was the observation that the meiotic divisions were synchronized, MI being the prevalent stage available on the slide. In the majority of MI cells, 13 bivalents of autosomes (AA) and 

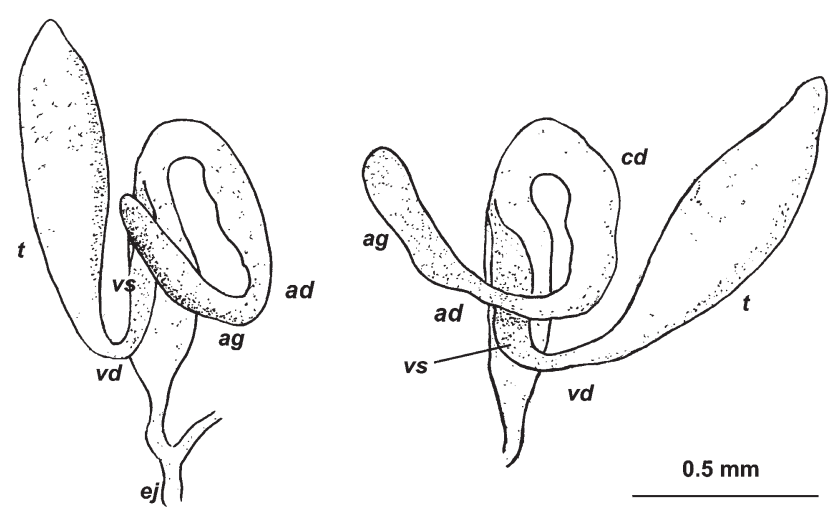

Fig. 1. Internal reproductive organs of male $X$. cascus. $\mathrm{t}$ - testis, vd - vas deferens, vs - vesicular seminalis, ag - accessory glands, ad - accessory gland ductus, cd - common ductus, ej - ductus ejaculatory.

a univalent X-chromosome were present $(\mathrm{n}=13 \mathrm{AA}+\mathrm{X})$. Based on a single specimen studied, the diploid karyotype of the species was interpreted as $2 n=26+X(0)$ in males. The chromosomes did not display any primary constrictions (the centromeres), thereby indicating their holokinetic nature (the kinetochore is spread over all or the most part of the chromosome). Bivalents ranged in size from large to small and the $\mathrm{X}$ was one of the smallest chromosomes in the set. Every bivalent formed a single terminal/subterminal chiasma. Bivalents were of an unusual fusiform appearance (Fig. 2a-c). Chromosomes displayed a large amount of AT-rich heterochromatin (Figs 2b-c, $4 \mathrm{a}$ ) as evidenced by the presence of DAPI-positive dots in prophase cells (Fig. 3) and bright DAPIpositive dots visible mainly on the telomeres of bivalents at MI. In some MI nuclei, one of the larger bivalents was completely DAPI-positive (Fig. 2c). Some meiotic irregularities, namely univalents (Fig. 4a, b, c) and bivalent associations (Fig. 4d), were present. In addition, MI nuclei displayed occasionally reduced number of bivalents (not shown), whereas anaphase I (AI) cells showed lagging chromosomes (Fig. 4e).

\section{DISCUSSION}

\section{Male reproductive system}

The internal reproductive organs in Peloridiidae are little known. Up until now, four species have been studied in this respect: Hemiodoecellus fidelis (Evans, 1937), Hemiodoecus leai China, 1924, Xenophyes cascus Bergroth, 1924 and Hackeriella veitchi $($ Hacker, 1932) = Hemiodoecus veitchi (Evans, 1937; Pendergrast, 1962; this study). Description and drawing of male reproductive organs are currently available for H. fidelis (Evans, 1937), H. veitchi (Pendergrast, 1962) and X. cascus (this study). Since all studied species are very similar in terms of the gross morphology of the male reproductive organs, this feature was earlier suggested (Pendergrast, 1962) to be of no significance during phylogenetic analysis.

In all the above species, testes consist of a single follicle. Within the Heteroptera, the number of follicles per testis varies from 1 to 7, testes with low numbers (from 1 to 3 ) being recorded mainly in the basal infraorders Dipsocoromorpha, Gerromorpha and Nepomoropha, whereas within the more advanced heteropteran lineages Cimicomorpha, Leptopodomorpha and Pentatomomorpha low numbers occur only sporadically (Pendergrast, 1957; Grozeva \& Kuznetsova, 1992; Grozeva \& Nokkala, 1996; Grozeva et al., 2013). On the other hand, within the Auchenorrhyncha, follicle numbers are highly variable ranging from 2 to 30 ; however, testes with only one follicle have not so far been found in any of the species tested (Kuznetsova et al., 1998, 2010). The number of the follicles has a potential bearing as a character during construction of an accurate phylogenetic system of the Hemiptera, although the data on this insect order are not sufficient as yet to define the characters polarity. This matter is worth mentioning here, but clearly demands further study.

\section{Bacteriomes}

According to Pendergrast (1962), the peloridiid species differ in the number of pairs of bacteriomes: 2 pairs in males of $\mathrm{H}$. $\mathrm{fi}$ delis (Müller, 1951), 3 in males of X. cascus and 4 in males of $H$. veitchi. Thus, our finding of 3 pairs in male $X$. cascus is in agreement with Pendergrast's data on this species. However in a recent study, Kuechler et al. (2013) reported 3 pairs of bacteriomes in males of 15 peloridiid species, including all the afore-mentioned species. Their data imply that the number of bacteriomes is 3 pairs throughout the family Peloridiidae, contradicting those of earlier authors. The only way to reconcile the contradiction between these results and those of Müller (1951) and Pendergrast (1962) would be to assume that the number of bacteriomes varies from individual to individual in peloridiid species, leading to different results in different studies. To eliminate further doubts, dissections of additional specimens per Peloridiidae species would be insightful.

\section{Karyotype}

In light of the data on $X$. cascus chromosomes presented here, all higher-level taxa of the Hemiptera are now known with respect to chromosome systems, although to differing extents. $X$. cascus was found to have holokinetic chromosomes like all other Hemiptera (Ueshima, 1979; Kuznetsova et al., 2011). The presence of holokinetic chromosomes can be considered as a synapomorphy of the whole Paraneoptera with the only exception of the order Thysanoptera, members of which are characterized by monocentric chromosomes (Brito et al., 2010). The distinctive property of holokinetic chromosomes is that they typically form just one or two chiasmata in meiosis (Nokkala et al., 2006) and this appeared to be the case in $X$. cascus in which a single chiasma per bivalent was formed. The karyotype formula of this species, $2 \mathrm{n}=26+\mathrm{X}(0)$, is common in the Auchenorrhyncha and occurs occasionally in the Heteroptera. Within the Auchenorrhyncha, this chromosomal complement is characteristic for the Fulgoromorpha (recorded for 120/308 species and 78/148 genera studied), while it was described in some Cicadomorpha also (Kuznetsova \& Aguin-Pombo, in press). In contrast, the $\mathrm{X}(0)$ sex determination system is rare within the Heteroptera, known only in separate representatives of both primitive (Dipsocoridae and Schizoperidae from the Dipscoromorpha: Grozeva \& Nokkala, 1996) and advanced (e.g. Reduviidae and Miridae from the Cimicomorpha: Kuznetsova et al., 2011) taxa. The majority of heteropterans displays an XY system (Ueshima, 1979; Papeschi \& Bressa, 2006; Kuznetsova et al., 2011). The question as to whether the common ancestor of the Heteroptera was $\mathrm{X}(0)$ or $X Y$ is still open (Kuznetsova et al., 2011). Ueshima (1979) has proposed that the XY system, despite its widespread occurrence in this group, is derived from the plesiomorphic $\mathrm{X}(0)$ condition. The fact that sex determination in non-heteropteran Hemiptera groups is predominantly X(0) (Blackman, 1995), seems to support this contention. On the other hand, Nokkala \& Nokkala (1983, 1984) formulated an alternative scenario, assuming that the $\mathrm{XY}$ mechanism was plesiomorphic in the Heteroptera, and the existence of $\mathrm{X}(0)$ species was due to repeated loss of the $\mathrm{Y}$ chromosome, i.e. the result of convergent evolution (homoplasy). Their arguments are based on the discovery of an XY species, Saldula orthochila (Fieber, 1859), among X(0) species in the ge- 

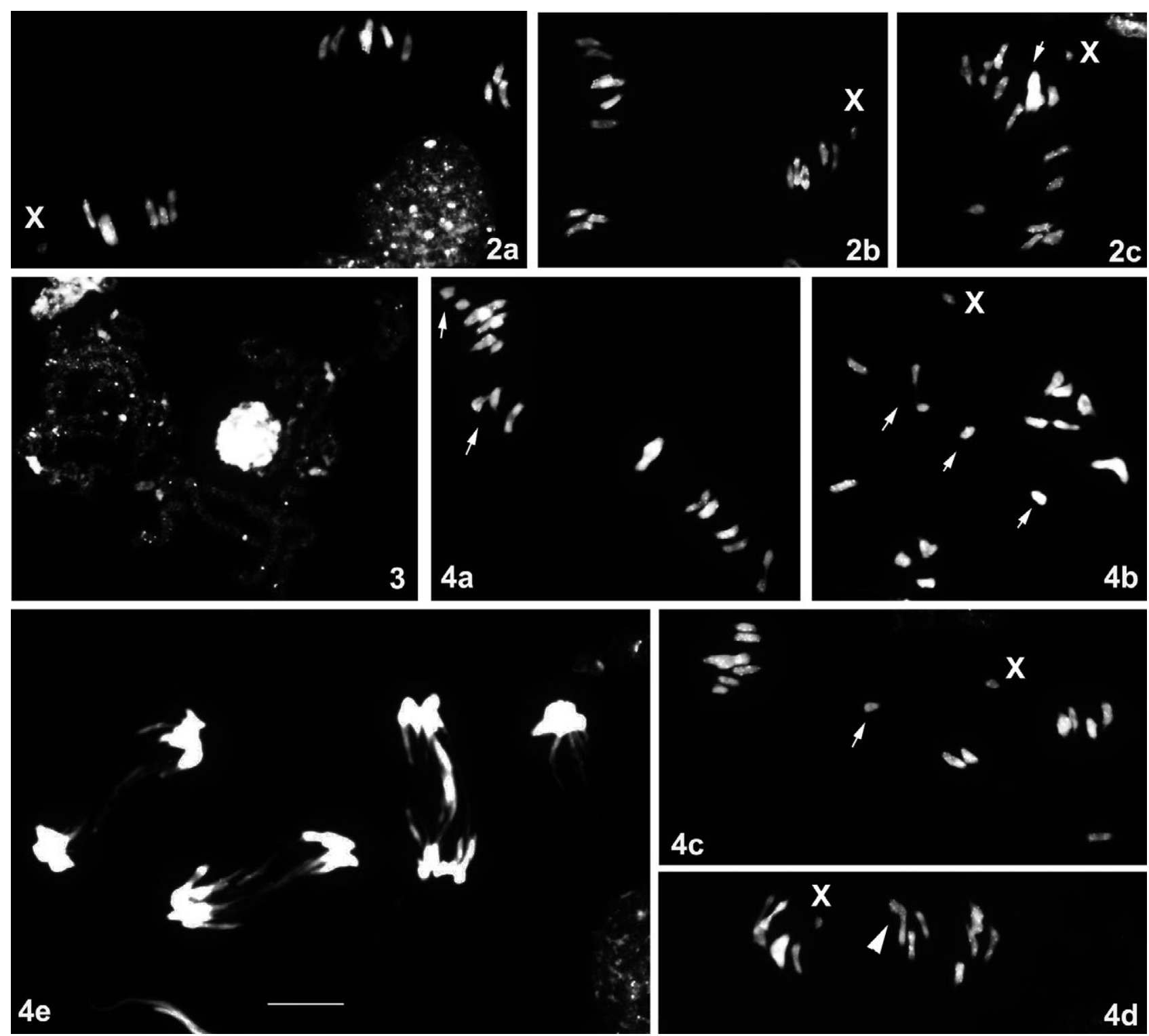

Figs 2-4. First meiosis in male $X$. cascus. 2a-c - first metaphase (MI) - fusiform bivalents with a single terminal/subterminal chiasma and univalent of $\mathrm{X}$ chromosome, $\mathrm{n}=13+\mathrm{X}(\mathrm{a}, \mathrm{b})$; chromosomes display a large amount of DAPI-positive AT-rich heterochromatin and one of the larger bivalents is completely DAPI-positive (c). 3 - prophase cells with DAPI-positive signals. 4a-e - meiotic irregularities: univalents (a, b, c); associations between bivalents (d); nuclei at first anaphase (AI) with lagging chromosomes (e). Arrows indicate univalents; arrowhead indicates associations. Bar $=10 \mu \mathrm{m}$.

nus Saldula Van Duzee, 1914 (Leptopodomorpha: Saldidae), and the sporadic occurrence of similar intrageneric $\mathrm{X}(0) / \mathrm{XY}$ variation within the heteropteran infraorders Gerromorpha, Cimicomorpha and Pentatomomorpha, indicating that the Y chromosome has a tendency to get lost during evolution.

Cytogenetic data on a single peloridiid species, obtained from a single specimen, as here shown, failed to provide any compelling evidence. Nevertheless, our new information clearly closes an important gap in our knowledge and allows some preliminary conclusions on the evolution of sex determination mechanism in the Hemiptera to be drawn, more especially that the XY-system has most likely been established within the Heteroptera. Further investigations on other peloridiid species and on representatives of the most primitive heteropteran infraorder Enicocephalomorpha are needed to throw more light on the matter.

ACKNOWLEDGEMENTS. The study was supported by the current project within the research agreement between Bulgar- ian Academy of Sciences and Russian Academy of Sciences (to SG and VK), and by grants from the RFBR (no. 14-04-01051) and programs of the Presidium of RAS "Gene Pools and Genetic Diversity" and "Origin of the Biosphere and Evolution of Geo-biological Systems" (to VK). We thank V. Gnezdilov and B. Anokhin, Zoological Institute, St. Petersburg, Russia for valuable advices, G. Gibbs, Victoria University, Wellington, New Zealand for collecting and sending us live specimens of X. cascus, and the anonymous reviewers, and language editor of the manuscript, $\mathrm{H}$. Loxdale, for their valuable comments and corrections.

\section{REFERENCES}

BerLese A. 1905: Apparecchio per raccogliere presto ed in gran numero piccoli artropodi. Redia 2: 85-90.

Blackman R.L. 1995: Sex determination in insects. In Leather S.R. \& Hardie J. (eds): Insect Reproduction. CRC Press, Boca Raton, pp. 57-94. 
Brito R.O., Affonso P.R.A.M. \& Silva J.C. JR. 2010: Chromosomal diversity and phylogenetic inferences concerning thrips (Insecta, Thysanoptera) in a semi-arid region of Brazil. Genet. Mol. Res. 9: 2230-2238.

BurCKHARDT D. 2009: Taxonomy and phylogeny of the Gondwanan moss bugs or Peloridiidae (Hemiptera, Coleorrhyncha). Dt. Entomol. Z. 56: 173-235.

Burckhardt D., Bochud E., Damgaard J., Gibbs G., Hartung V., Larivière M.-C., Wyniger D. \& ZÜrcher I. 2011: A review of the moss bug genus Xenophyes (Hemiptera: Coleorrhyncha: Peloridiidae) from New Zealand: systematics and biogeography. - Zootaxa 2923: 1-26.

Cui Y., Xie Q., Hua J., Dang K.A.I., Zhou J., Liu X., WAng G., Yu X.I.N. \& BU W. 2013: Phylogenomics of Hemiptera (Insecta: Paraneoptera) based on mitochondrial genomes. - Syst. Entomol. 38: 233-245.

Evans J.W. 1937: A new species of Peloridiidae (Hemiptera, Homoptera) from Tasmania. - Proc. R. Entomol. Soc. Lond. (B) 6: 107-10.

Evans J.W. 1982: A review of present knowledge of the family Peloridiidae and new genera and new species from New Zealand and New Caledonia (Hemiptera: Insecta). — Rec. Austral. Mus. 34: 381-406.

Grozeva S.M. \& KuzNetsova V.G. 1992: The reproductive system of some bug families (Heteroptera, Pentatomomorpha). In Bennettová B., Gelbič I \& Soldán T. (eds): Advances in Regulation of Insect Reproduction. Institute of Entomology, Czech Acad. Sci., České Budějovice, pp. 97-102.

Grozeva S. \& Nokkala S. 1996: Chromosomes and their meiotic behavior in two families of the primitive infraorder Dipsocoromorpha (Heteroptera). - Hereditas 125: 31-36.

Grozeva S., Kuznetsova V., Simov N., Langourov M. \& DaLAKCHIEVA S. 2013: Sex chromosome pre-reduction in male meiosis of Lethocerus patruelis (Stål, 1854) (Heteroptera, Belostomatidae) with some notes on the distribution of the species. - ZooKeys 319: 119-135.

Kuechler S.M., Gibbs G., Burckhardt D., Dettner K. \& HarTUNG V. 2013: Diversity of bacterial endosymbionts and bacteria-host co-evolution in Gondwanan relict moss bugs (Hemiptera: Coleorrhyncha: Peloridiidae). - Environ. Microbiol. 15: 2031-2042.

Kuznetsova V.G., MaryańsKa-Nadachowska A., Yang C.-T. \& O'Brien L.B. 1998: Karyotypes, sex-chromosome systems, and testis structure in Fulgoroidea (Auchenorrhyncha, Homoptera, Insecta). - Folia Biol. (Kraków) 46: 23-40.
Kuznetsova V.G., Maryańska-Nadachowska A. \& Gnezdilov V.M. 2010: Meiotic karyotypes and testis structure of 14 species of the planthopper tribe Issini (Hemiptera: Fulgoroidea, Issidae). - Eur. J. Entomol. 107: 465-480.

Kuznetsova V.G., Grozeva S., Nokkala S. \& Nokkala C. 2011: Cytogenetics of the true bug order Cimicomoropha (Hemiptera: Heteroptera): a review. - Zookeys 154: 31-70.

Kuznetsova V. \& Aguin-Pombo D. (in press) Comparative cytogenetics of Auchenorrhyncha: a review. In Badmin J. \& Webb M. (eds): Leafhoppers of the World and their relatives.

Larivière M.-C., Burckhardt D. \& Larochelle A. 2011: Peloridiidae (Insecta: Hemiptera: Coleorrhyncha). In: Fauna of New Zealand 67. Landcare Research, Auckland, 78 pp.

MÜlLER H.J. 1951: Über die intrazelluläre Symbiose der Peloridiide Hemiodoecus fidelis Evans (Homoptera: Coleorrhyncha) und ihre Stellung unter den Homopterensymbiosen. - Zool. Anz. 146: 150-167.

NokKala S. \& NoKkala C. 1983: Achiasmatic male meiosis in two species of Saldula (Saldidae, Hemiptera). - Hereditas 99: 131-134.

Nokkala S. \& Nokkala C. 1984: The occurrence of the X0 sex chromosome system in Dictyonota tricornis (Schr.) (Tingidae, Hemiptera) and its significance for concepts of sex chromosome system evolution in Heteroptera. - Hereditas 100: 299-301.

NokKala S., Kuznetsova V.G., Maryanska-Nadachowska A. \& NoKkala C. 2006: Holocentric chromosomes in meiosis. II. The modes of orientation and segregation of a trivalent. Chromos. Res. 14: 559-565.

PAPesChi A.G. \& BREssa M.J. 2006: Evolutionary cytogenetics in Heteroptera. - J. Biol. Res. 5: 3-21.

Pendergrast J.G. 1957: Studies on the reproductive organs on the Heteroptera with a consideration of their bearing on classification. - Trans. R. Entomol. Soc. Lond. 109: 1-63.

Pendergrast J.G. 1962: The internal anatomy of the Peloridiidae. - Trans. R. Entomol. Soc. Lond. 114: 49-65.

TULLGREN A. 1918: Ein sehr einfacher ausleseapparat für terricole tierfaunen. Z. Angew. Entomol. 4: 149-150.

Ueshima N. 1979: Hemiptera II. Heteroptera. In John B. (ed.): Animal Cytogenetics 3, Insecta 6, Gebrüder Borntraeger, Berlin, pp. 1-118.

Received November 25, 2013; revised and accepted December 31, 2013 Prepublished online February 25, 2014 